\title{
Learning Sampling and Reconstruction of signals through PBL tasks
}

\author{
Oscar Iván Higuera-Martínez, Ph.D. Student ${ }^{1}$, Liliana Fernandez-Samacá, PhD. ${ }^{1}$ \\ ${ }^{1}$ Universidad Pedagógica y Tecnológica de Colombia, Signal Processing Research Group DSP-UPTC, \\ oscar.higuera@uptc.edu.co, liliana.fernandez@uptc.edu.co
}

\begin{abstract}
This article presents the design and implementation of $P B L$ tasks, for improving the understanding of sampling and reconstruction of signals. This implementation focuses on the execution of a mini project in the course of digital signal processing. The paper presents the backward design of theme in the course, the planning of the activities, and the results of the implementation. Likewise, it describes an analysis of the effects of PBL tasks on students' concepts; the obtained results demonstrate that they can solve problems of application in a different way. Evaluation of the system has been done in the period of one semester on the test group of 20 students.
\end{abstract}

\section{Keywords-Engineering Education; Project-Based Learning, Signal Processing Education.}

\section{INTRODUCTION}

Currently, the research on approaches for teaching and learning in engineering education is a topic of great interest; especially, if those are related to the use of projects; hence, the concern to start this work about how to facilitate the use of projects in engineering courses. At the end of the $60 \mathrm{~s}$, the problem-based learning experience appeared at the medical school of MacMaster, Canada, which inspired other medical schools to implement similar programs, among them Maastricht in the Netherlands. In parallel with the work done at MacMaster, the University of Aalborg in Denmark, opened in 1974, works on project-based learning, which extends to other universities in Germany and the Netherlands [1]. Another area in which PBL models have been developed is Architecture, highlighting the 'Block Model' of the Delf University of Technology in the Netherlands that was also applied in engineering and some science programs and health particularly in northern Europe. The PBL has spread to many universities and programs throughout the world and in Latin America.

Nowadays, there are Universities whose entire educational model is based on PBL; others have put their efforts on models based on Innovation creating exciting scenarios for improving the student learning. However, many of our universities in Latin America have a traditional education, centered on teaching, then appears a critical query, how to change the traditional approach taking advantage of the experience and infrastructure of our Universities? This paper suggests a way to begin the change showing an example for a course of Signal Processing.

Problem-based learning is where the problem is the cornerstone of the learning process, contrary to project-based learning in which the problem is only the starting point, and the project is the navigation chart to arrive at the solution of the problem. In project-based learning, there are resource and time constraints. In the case of engineering training, learning around the project is more common. Other strategies that coincide with some characteristics of the PBL are Solving Problem, problem-solving learning, scenario-based learning, Inquiry-based and enquiry-based learning, problem-oriented learning, work-based learning, and action learning [2].

Some of the contributions on PBL are oriented to a particular subject of a curriculum, such as computation [3], industrial electronics and electrical power [4], [5], Signal processing and VHDL [6]-[11], where the different authors work examples of the environment for hardware oriented project-based courses and control [12]-[14]. These examples present successful PBL models focused on single courses. Other cases related to Signals show tools that support the teaching, for example in [15], where authors describe the use of smartphones for implementing digital signal processing algorithms in real-time using ARM processors of smartphones.

Otherwise, the interest of this paper is to design a PBL approach for a topic of a subject and later, extend this approach to the whole course. In the beginning, the approach stresses on the understanding of sampling and reconstruction of signals, since usually, the concepts in digital signal processing become complex and mathematically challenging for some students [8]; especially, when they need to consider the temporal and the frequency effects of signals. The focus of the proposed PBL seeks to makes students able to carry out a work that allows improving the understanding of the concepts, problem-based learning promotes self-directed learning, collaborative work; this case search that the problem is solved by a group of students working in coordination and reduce the repetition rate of this course [16]

This article is organized in four sections; Section 1 presents an introduction to the topic and a general outline of the research in the area. In section 2, authors describe the PBL

Digital Object Identifier (DOI):

http://dx.doi.org/10.18687/LACCEI2019.1.1.310

ISBN: 978-0-9993443-6-1 ISSN: 2414-6390

$17^{\text {th }}$ LACCEI International Multi-Conference for Engineering, Education, and Technology: "Industry, Innovation, And Infrastructure for Sustainable Cities and Communities", 24-26 July 2019, Jamaica. 
intervention defined as tasks for the chosen theme, sampling and reconstruction of signals. In section 3, authors summarize the implementation of PBL approach; and finally, in section 4, the main results are discussed.

\section{DESIGN LEARNING OF SAMPLING AND RECONSTRUCTION OF SIGNALS}

For starting the design of the PBL experience for sampling and reconstruction of signals, which belongs to the area of digital signal processing (DSP), researchers began with the current content of the subject established in the syllabus. Researchers carried out a 'Backward Course Design' and observed the Learning Objectives, linking them with the contents.

Researchers took as a case study the DSP course, which is an eighth-semester course of the Electronic Engineering program at Universidad Pedagógica y Tecnológica de Colombia (UPTC), Sogamoso, Colombia. This course provides concepts and applications of digital signal processing, and it is characterized by using a high mathematical analysis and abstract conceptualization. This type of analysis is difficult for some students, who in most cases present deficiencies in the final the understanding of some concepts. When students are going to apply these concepts in a real problem, they have many issues to put the knowledge into practice; especially, for converting the mathematical model into an algorithm that can be implemented applying all the concepts dealt in the subject.

The course design (implemented to the first semester of 2018) considered a master class, where students carried out extra activities focused on sharing different developments about the application of the concepts in a set of examples common for all them. Likewise, students executed lab practices mainly as independent work under the advisory of the teacher.

For carrying out the design, it was necessary to identify the curricular priorities and desired results, that is, what should students know, understand, and be able to do?

\section{A Curricular Priorities.}

To define the curricular contents, researchers determine the importance of what the student should have as a result at the end of each unit and at the end of the course, which after a revision and using the model of Wiggins \& McTighe [17] produced as a result the curricular priorities, where aspects related to the important, the required and the optional for each unit of the course are defined, see in Figure 1.

\section{B Learning Objectives.}

Based on the curricular priorities' analysis, authors discuss the learning objectives; these objectives are the basis for the PBL experience design. A minimum of activities necessary to evaluate these learning objectives also is determined along to some rubrics used in the assessment.

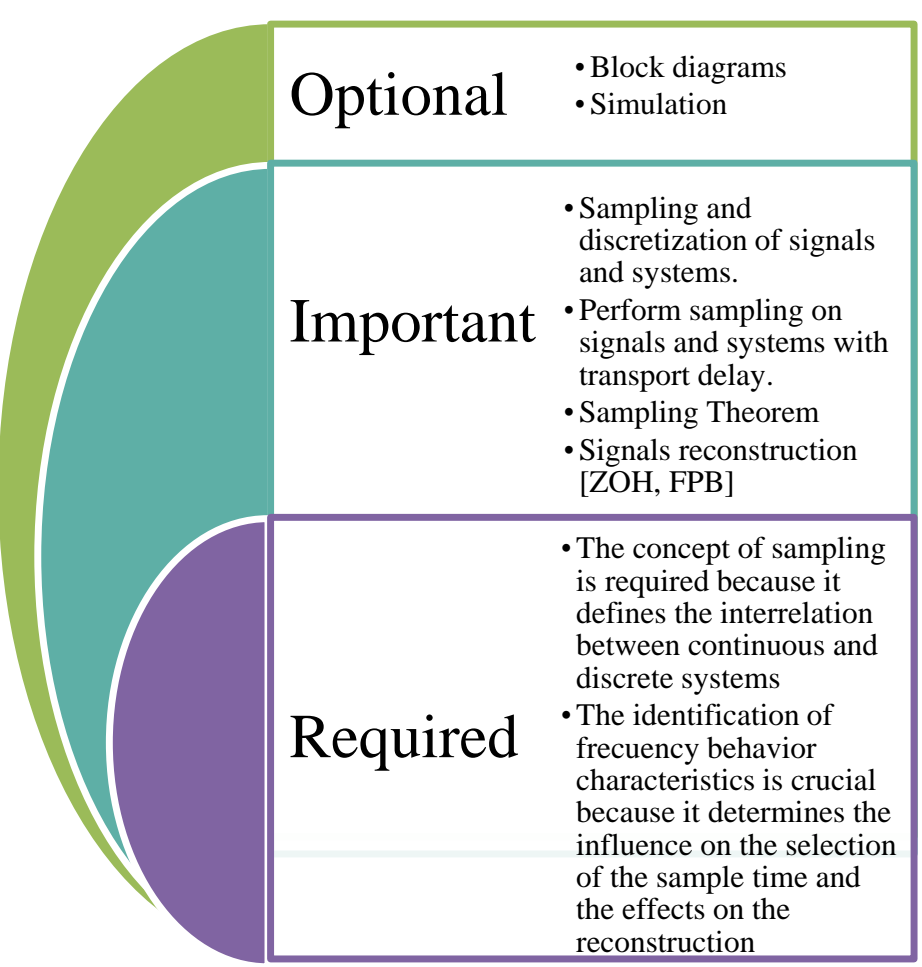

Fig. 1: Curricular Priorities for Sampling and reconstruction of Signals

Considering revised Bloom's taxonomy, and the curricular contents, researchers determined the knowledge dimension in procedural level, and the cognitive process in analysis level, defining the learning outcomes for 'sampling and reconstruction of signals. Which are the following:

At the end of the course, the student should be able to:

.LO1. Analyze the effect of sampling and reconstruction on signals and systems.

LO2. Identify the difference between an analog model and a discrete model.

LO3. Apply the discretization technique according to the proposed problem.

LO4. Describe the main implications of discretization. (Understand)

LO5. Interpret the behavior of the different signals presented in the systems, either continuous or discrete. (Understand)

C PBL Intervention design 
Based on the Backward Design, that takes into account the learning objectives, the assessment, and the pedagogy, a more detailed description of the design of the PBL experience will be made for the unit (sampling and reconstruction of signals) under consideration. This experience is conceived to emphasize in each specific unit with project tasks.

The main objectives of this PBL intervention are i) Change the teaching practice of the Digital Signal Processing course of the Uptc Electronic Engineering program, so that students have more autonomy in their learning process. And ii) Design learning activities that involve students in the subject so that they can understand the concepts treated more easily.

The teaching goals for the chosen courses are i) strengthen the knowledge and skills of students of the digital signal-processing course of implementing sampling and reconstruction circuits. And ii) Promote the development of cross-cutting skills, especially cooperative work, as a strategy to facilitate the learning process and communication skills, principal to make oral presentations and write technical reports.

As a general learning objective, it was defined: "Students can apply theoretical knowledge in practical exercises related to the subject."

\section{Pedagogy}

Students were provided from the first day of classes the bibliography of the subject; this is available in the Library of the University, as well as, a summary of the class notes of the teacher. For the development of the subject, there are eight sessions of 2 hours (in the classroom), three sessions of 2 hours of practice in the Laboratory, and additional tutoring by the teacher (4 hours per week).

The development of the syllabus is carried out by using lectures and experiences where the student is actively involved in the development of the subject), such as:

1. Workshops, the student works for 10 or 15 minutes in a specific theme.

2. Hands-On activities. This seeks that the student understands the effects of sampling on a signal.

3. 3. Simulation practices of Sampling and Aliasing Theorem, this practice devotes to use a simulation block for observing the frequency spectrum and the effects of sampling frequency on the reconstruction of a signal.

4. Lab practices, where students work in teams of 3 members; there, students make the discretization of a signal and presents a theoretical analysis and a technical report that contents the corresponding tests.
At the end of the class period when the activities conclude, it applies an evaluation, by using a questionnaire, for knowing the students' feedback and planning the necessary adjustments.

Researchers designed activities for meeting each one of the learning objectives, identifying the necessary elements a considering a formative assessment stage, so students have the required feedback for overcoming the weaknesses founded so far. An example of an activity for learning objective 1, is presented as follows:

Activity 1: Analyze the effect of sampling on the reconstruction of the signals and systems, and evaluate whether the selection presented is in accordance with the criteria and concepts, or if any type of modification is necessary.

This activity is divided into three stages, the first intends to conceptualize a solve questions, the second stress on presenting the advance and give feedback to students about the partial results, and finally, the third one devotes to discuss the results of the activity. This sequence is followed for all activities at seeking to achieve the Learning Outcomes.

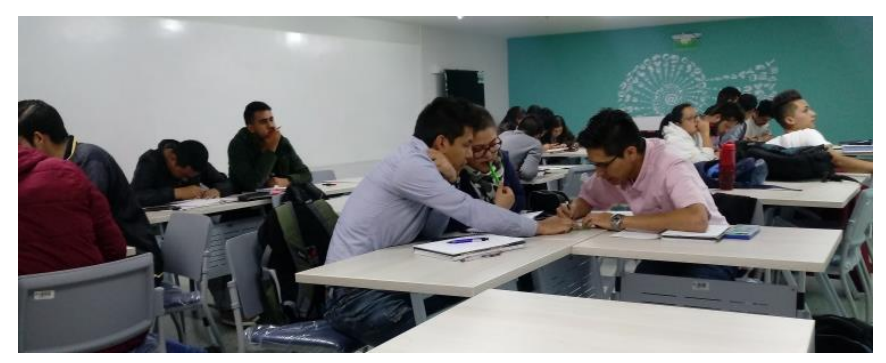

Fig. 2 The students realize a class workshop on the spectrum of signals sampled.

\section{IMPLEMENTATION}

The PBL implementation was developed according to a master plan proposed (course plan). Taking into account that the proposed PBL intervention was designed as an aligned activity. The activities of the project are related directly to the actions defined for dealing with the theme, especially in the development of, i) Hands-on and Workshops and ii) Cooperative sessions (group work).

When students take the Digital Signal Processing (DSP) course, they have already studied calculus, the introduction to signals and systems, and some courses of analog electronics and digital electronics. However, advanced courses of electronics are not prerequisites of DSP, and it is usual that some students take this course without complete knowledge of electronic (e.g., microcontrollers, digital electronics), which makes difficult to understand some real applications. 
For the class sessions, an active learning classroom that facilitates the interaction among students since its flexibility allow different configurations for individual or group work moreover, the classroom has Wi-Fi connection, enough electrical connections for transforming it into a lab, and audiovisual aids such as video beam and TVs, which support the development of workshops and Hands-On.

The course is developed considering, that the main objective is that the student to understand the concepts of sampling and reconstruction of signals. For this purpose are designed Workshops, Hands-On activities, for example, its realized a workshop about the concept of the effect of the sampling in a signal of the known spectrum (Fig 2), simulation practices are carried out, and a final project to understand the concepts. The teacher, who in addition to designing the activities described above, accompanies all the events, realize the presentation of some complementary topics through lectures.

For the final project of the unit, which was supported by the activities carried out during the course, teachers defined two deliveries: i) the design and analysis of a signal sampling circuit, and ii) the design and implementation of two reconstruction circuits of signals, which were focused on evaluating all previous activities and strengthening the concepts. For this final activity, the teams presented a Matlab® simulation of the corresponding circuit (chosen and designed under specifications), as well as its implementation in a circuit simulation package and finally, its application on a protoboard.
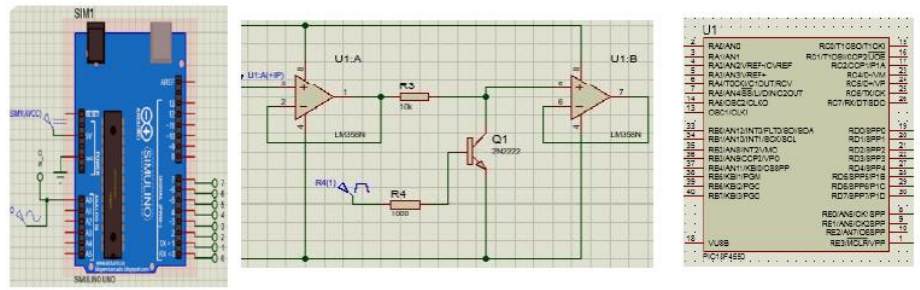

Fig. 3 The platforms used by students to simulate problem solution (Arduino, discrete elements, and microcontroller)

\section{RESULTS}

After carrying out the activities planned for the unit, the effectiveness of the final project delivered was evaluated. Figure 3 shows three examples of the technologies students selected to implements the solution to the problem (Simulation results). Researchers observed that his implementation changed according to their level of previous knowledge; for example, one team implemented a circuit by using discrete components, as much for the sampling as for the reconstruction, while other groups implemented a solution by a microcontroller or Arduino. All groups met the requirements fully.

During the development of the project, there were different sessions to solve doubts about the implementation that each group carried out and solve question or problems. The final projects of the unit are presented to the teacher, where only the proper functioning of the same is reviewed, in Fig. 4, we observe a simulation of the sampled circuit realized by one team. In Fig. 5 and 6 are present the results of two groups, implemented with different platforms and those who met the requirements given in the proposed problem.
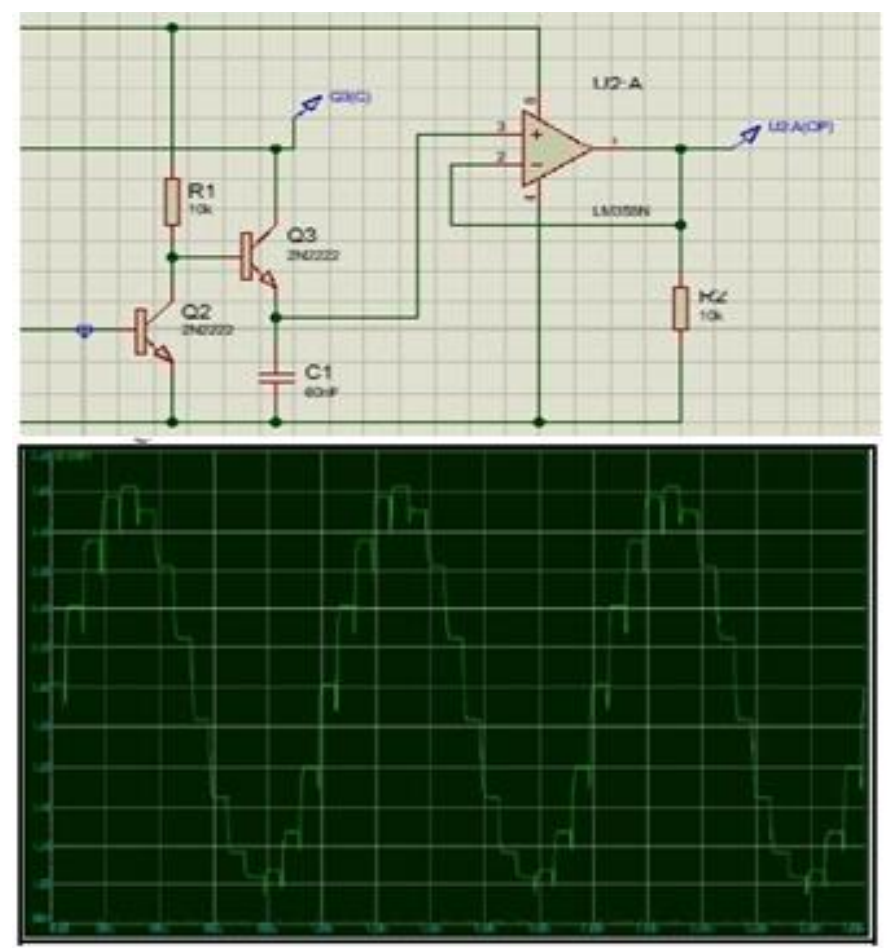

Fig. 4 Results of signal reconstruction simulation presented by a team, using discrete devices (transistors, resistors, and capacitors)

The final presentation realized with the purpose that the different groups socialize their experiences among them, for which the following activity was carried out:

Teams that used different technological platform were grouped to present the project, (considering that the implementation was not done in the same platform) Figure 2 and 3, show two examples of the circuits implemented by the students. In this activity, Team 1 presented their work to Team 2 , and Team 2 to Team 1 . At the end of the oral presentation, the two groups meet to discuss the work done. Later, the teacher rotated the groups and thus to have two different groups for the evaluation; however, in this case, they did not present their results, instead of that, they discussed founded problems during the implementation of the project. Finally, each student analyzed, individually, the executed work. 


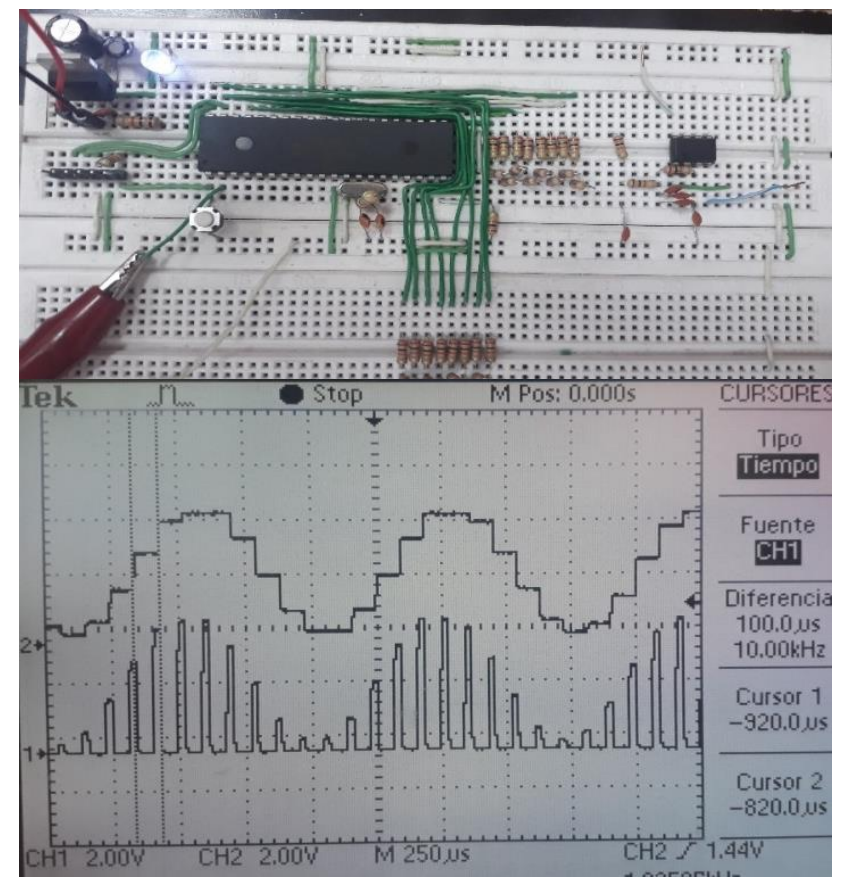

Fig. 5 Result by a team using a microcontroller device. (Circuit and signals)

Each student was asked to write down their assessment and the results of the activity, most of the students highlighted the importance of this kind of experiences, and its relevance to understanding the sampling and reconstruction of signals, some comments were:

"the activity was so good,"

"we could understand the design of a sampling circuit and its effects on signals reconstruction."

Students also emphasize that the development of the activity has been relevant to learn the subject; Some comments on how they impacted the activities in these, were:

"I liked how the activities and classes of the subject were developed because it was interactively generating interest in the topics,"

"It is much more enriching to see the way in which they can practically implement the theoretical knowledge seen in class and make the feedback."

\section{CONCLUSION}

The results of the questionnaire show that students accepted the designed PBL intervention and manifested that it helped them to achieve the learning objectives. This means that students consider that the PBL intervention facilitated their knowledge about the dealt topic. Moreover, the PBL intervention improved their self-confidence, teamwork abilities, and self-management to construct by themselves the knowledge. Likewise, it is important to highlight, that teacher also remarked the intervention enhanced the deep learning of students, which was observed in the achieved presented results in the technical report, and from oral presentations and discussions of the teams.

It is necessary to carry out these activities in different subjects of the course, in order to achieve better learning of the students, and a more significant application of the concepts in the solution of engineering problems, for which the implementation of activities and project will be structured in the course of Signal Processing.

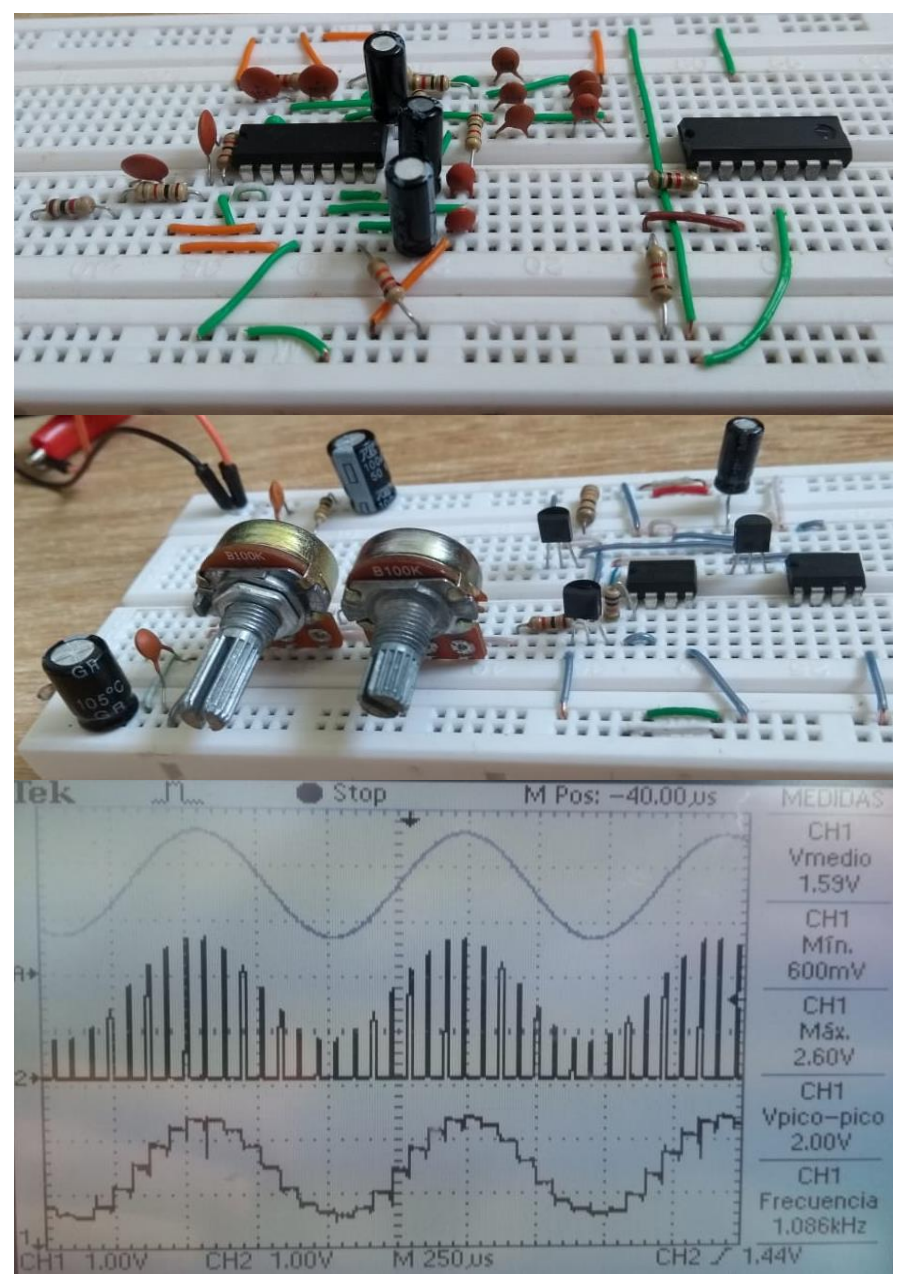

Fig. 3 Results presented by a student team, using discrete devices (transistors, resistors, and capacitors)

\section{REFERENCES}

[1] E. De Graaff and A. Kolmos, Management of Change: Implementation of Problem-Based and Project-Based Learning in Engineering. 2007.

[2] A. Kolmos, E. De Graaff, and X. Du, "Diversity of PBL-PBL learning principles and models," Res. PBL Pract. Eng. Educ., pp. 9-21, 2009.

[3] M. Indiramma, "Project based learning - Theoretical foundation of computation course," in Proceedings of 2014 International Conference on Interactive Collaborative Learning, ICL 2014, 2015, pp. 841-844.

[4] N. Hosseinzadeh and M. R. Hesamzadeh, "Application of project-based

$17^{\text {th }}$ LACCEI International Multi-Conference for Engineering, Education, and Technology: "Industry, Innovation, And Infrastructure for Sustainable Cities and Communities", 24-26 July 2019, Jamaica. 
learning (PBL) to the teaching of electrical power systems

engineering," IEEE Trans. Educ., vol. 55, no. 4, pp. 495-501, 2012.

[5] J. Quesada et al., "Combining moodle and redmine as e-learning tools in Project Based Learning of Industrial Electronics," in Proceedings 2013 7th IEEE International Conference on e-Learning in Industrial Electronics, ICELIE 2013, 2013, pp. 86-91.

[6] V. Kiray, S. Demir, and M. Zhaparov, "Improving Digital Electronics Education with FPGA technology, PBL and Micro Learning methods,' in Proceedings of 2013 IEEE International Conference on Teaching, Assessment and Learning for Engineering, TALE 2013, 2013, pp. 445448.

[7] A. Kumar, S. Fernando, and R. C. Panicker, "Project-based learning in embedded systems education using an FPGA platform," IEEE Trans. Educ., vol. 56, no. 4, pp. 407-415, 2013.

[8] F. Kulmer, C. G. Wurzer, and B. C. Geiger, "The Magnitude Response Learning Tool for DSP Education: A Case Study," IEEE Trans. Educ., vol. 59, no. 4, pp. 282-289, 2016.

[9] F. Machado, S. Borromeo, and N. Malpica, "Project based learning experience in VHDL digital electronic circuit design," in 2009 IEEE International Conference on Microelectronic Systems Education, 2009. pp. 49-52.

[10] I. Milentijevic and V. Ciric, "Project-based learning environment for special purpose DSP architectures," in 2007 9th International Symposium on Signal Processing and Its Applications, 2007, pp. 1-4.

[11] A. Pardo, "Problem-based learning combined with project-based learning: A pilot application in digital signal processing," in Proceedings of XI Tecnologias Aplicadas a la Ensenanza de la Electronica (Technologies Applied to Electronics Teaching), TAEE 2014, 2014.

[12] S. Yuan and Z. Shen, "Study and application of PBL in control system course," in 2012 2nd International Conference on Consumer Electronics, Communications and Networks, CECNet 2012 Proceedings, 2012, pp. 2874-2877.

[13] L. Fernández-Samacá, J. M. Ramírez, and M. L. Orozco-Gutiérrez, "Project-based learning approach for control system courses," Control. y Autom., vol. 23, no. 1, pp. 94-107, 2012.

[14] L. Fernandez-Samaca, J. M. R. Scarpetta, O. O. Rodriguez, and E. F. Mejia, "PBL model for single courses of control education," Int. J. Eng. Educ., vol. 33, no. 3, pp. 963-973, 2017.

[15] N. Kehtarnavaz, S. Parris, and A. Sehgal, "Using smartphones as mobile implementation platforms for applied digital signal processing courses," in 2015 IEEE Signal Processing and Signal Processing Education Workshop (SP/SPE), 2015, pp. 313-318.

[16] O. Higuera-Martinez, "Deserción estudiantil en Colombia y los programas de ingeniería de la Uptc seccional Sogamoso.," Ing. Investig. y Desarro., vol. 17, no. 1, pp. 70-76, 2017.

[17] G. Wiggins and J. McTighe, What is backward design. Understanding by design, 1st ed. ASCD, 1998.

$17^{\text {th }}$ LACCEI International Multi-Conference for Engineering, Education, and Technology: "Industry, Innovation, And Infrastructure for Sustainable Cities and Communities", 24-26 July 2019, Jamaica. 